\title{
Studies of the structure and chemistry of SBA-15 organosilicas functionalized with amine, thiol, vinyl and phenyl groups
}

\author{
Mariusz Barczak • Andrzej Dąbrowski • \\ Stanisław Pikus · Janusz Ryczkowski · Piotr Borowski • \\ Maciej Kozak
}

Received: 4 May 2010 / Accepted: 6 July 2010 / Published online: 24 August 2010

(C) The Author(s) 2010. This article is published with open access at Springerlink.com

\begin{abstract}
SBA-15 organosilicas containing amine, thiol, vinyl and phenyl pendant groups were synthesized by cocondensation of tetraethoxysilane and appropriate alkoxysilanes in the presence of Pluronic P123 surfactant. The obtained materials have usually well-developed porous structure-values of specific surface area are in the range $820-950 \mathrm{~m}^{2} / \mathrm{g}$. Sizes of the ordered mesopores are in the range 7.5-9.1 nm while the interconnecting pores are 2.3$3.1 \mathrm{~nm}$ in size. It was establish that size of the mesopores strongly depends even on small amounts of co-monomers co-condensing with tetraethoxysilane. Several instrumental techniques such as infrared spectroscopy, X-ray diffraction, nitrogen sorption measurements, elemental analysis, transmission electron microscopy. FT-IR photoacoustic spectroscopy (FT-IR/PAS) was used to determine chemical composition of the final materials and to monitor the efficiency of the template removal.
\end{abstract}

Keywords Organosilicas - SBA-15 - Ordered mesoporous materials · OMOs · Functionalization · Pluronic P123 . Adsorption · Porosity

In honor of Professor Andrzej Waksmundzki on the occasion of his $100^{\text {th }}$ birthday.

M. Barczak ( $\varangle)$ · A. Dąbrowski · S. Pikus · J. Ryczkowski · P. Borowski

Faculty of Chemistry, Maria Curie-Sklodowska University, Maria

Curie-Sklodowska Sq. 3, 20-031 Lublin, Poland

e-mail: mbarczak@poczta.umcs.lublin.pl

M. Kozak

Department of Macromolecular Physics, Adam Mickiewicz

University, Umultowska Str. 85, 61-614 Poznań, Poland

\section{Introduction}

During the last fifteen years a significant progress has been achieved in the field of ordered mesoporous silicas (OMSs) (Kresge et al. 1992; Beck et al. 1992). Especially, the SBA15 materials have become ones of the most popular ordered silica nanomaterials for several reasons: large mesopores (even up to $15 \mathrm{~nm}$ ), thicker pore walls and presence of the network of irregular interconnecting micropores (Zhao et al. 1998a, 1998b; Goltner et al. 1998). Moreover these materials have higher thermal and hydrothermal stabilities than MCM-41 materials due to thicker mesopores walls. SBA-15 materials are usually synthesized under strong acidic conditions in the presence of amphiphilic triblock copolymerPluronic P123. The synthesis is carried out via controlled hydrolysis and condensation of tetraethoxysilane (TEOS) followed by removal of the polymeric template by either extraction with ethanol and acid or calcination at elevated temperatures.

Possibility of introduction of different organic moieties into the framework as well as onto the surface makes OMSs very attractive for sensing devices, environmental applications and particularly, for catalytic and adsorption processes (Andersson et al. 2004; Olkhovyk et al. 2004; Rosenholm et al. 2004; Gierszal et al. 2005; Olkhovyk and Jaroniec 2005). Such organically modified materials are known as ordered mesoporous organosilicas (OMOs). There are two main approaches for the surface functionalization: postsynthesis grafting i.e. attaching desired groups to the surface of template-free OMS, and direct co-condensation of silica precursor and functionalized co-monomers. Such functionalization leads to the materials differing in the reactivity, pore accessibility and distribution of organic groups (Grudzien et al. 2006). The co-condensation route seems to be particularly attractive because it affords to control simul- 
Fig. 1 Structure of ordered mesoporous silicas (left) and ordered mesoporous organosilicas (right)

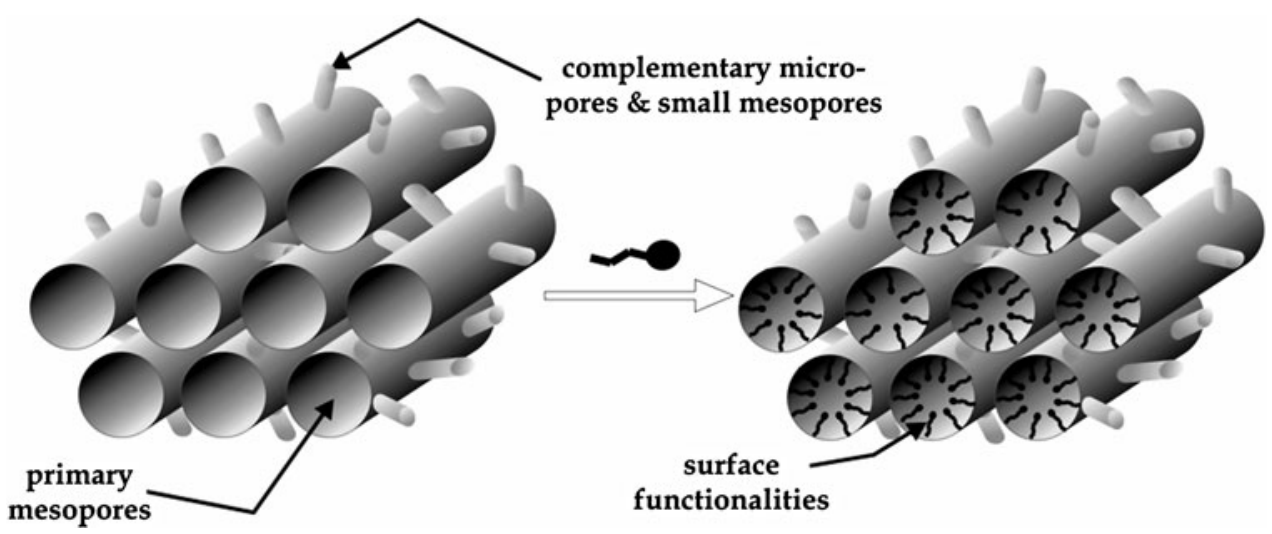

taneously the surface and structural properties of the resulting OMOs. The structure of SBA-15 material and the idea of functionalization have been schematically presented in Fig. 1.

Due to the fact that OMOs are so attractive materials from the point of view of the modern materials science there is a big demand for reliable techniques of characterization of their structural and chemical properties. Among them, IR spectroscopy is one of the most frequently used techniques to study the chemical composition. It can be also used for the monitoring the template removal process, which is important and non-trivial problem.

Here, we briefly describe the synthesis, characterization of SBA-15 materials and application of FT-IR/PAS to study their chemical composition and the efficiency of template removal. The reported materials were also characterized by Raman spectroscopy, powder X-ray diffraction (XRD), nitrogen sorption measurements, elemental analysis and transmission electron microscopy (TEM).

\section{Experimental part}

\subsection{Materials}

Initially the following compounds were used: tetraethoxysilane: $\left(\mathrm{C}_{2} \mathrm{H}_{5} \mathrm{O}\right)_{4} \mathrm{Si}$ (TEOS, 96\%, ABCR), 3-mercaptopropyltriethoxysilane (MTES, 95\%, ABCR), 3-phenyltriethoxysilane (PTES, 98\%, ABCR), vinyltriethoxysilane (VTES, 98\%, ABCR), 3-aminopropyltriethoxysilane (ATES, 98\%, ABCR), poly(ethylene oxide)-blockpoly(propylene oxide)-block-poly(ethylene oxide) triblock copolymer ( $\mathrm{EO}_{20} \mathrm{PO}_{70} \mathrm{EO}_{20}$, Pluronic P123, P123, BASF), hydrochloric acid (37\%, POCH), ethanol (99.8\%, POCH). Deionized water (DW; resistivity $<17.5 \mathrm{M} \Omega \mathrm{cm}$ ) was obtained using Millipore ion-exchange purification system. All chemicals were used as received without further purification.

\subsection{Synthesis}

Syntheses of all channel-like mesoporous SBA-15 silicas were performed by co-condensation of TEOS and proper organotrialkoxysilane (ATES, MTES, PTES or VTES) in the presence of Pluronic P123. All materials were synthesized by one-pot route using similar synthesis procedure. In a model synthesis, $2 \mathrm{~g}$ of P123 was dissolved in $60 \mathrm{ml}$ of $2 \mathrm{M} \mathrm{HCl}$ and $11 \mathrm{ml}$ of deionized water under vigorous stirring at $40^{\circ} \mathrm{C}$. After $8 \mathrm{~h}$ of stirring a TEOS was added dropwise to this solution. After 15 minutes a proper organotrialkoxysilane (ATES, MTES, PTES or VTES) was added dropwise. The resulting mixture was stirred at $40{ }^{\circ} \mathrm{C}$ for $24 \mathrm{~h}$ and aged at $100^{\circ} \mathrm{C}$ for next $48 \mathrm{~h}$. The obtained white solid was thoroughly washed with deionized water, filtered and dried at $70^{\circ} \mathrm{C}$. The template was removed by fourfold extraction with acidic absolute ethanol $(99.8 \%)$ at $70^{\circ} \mathrm{C}$.

The designation of the samples and the initial ratio of monomers used in the synthesis were as follows: $\boldsymbol{S 1}$ (TEOS: $20 \mathrm{mmol}$ ), $\boldsymbol{S} 2$ (TEOS: $19 \mathrm{mmol}$, ATES: $1 \mathrm{mmol}$ ), $\boldsymbol{S} \mathbf{3}$ (TEOS: 19 mmol, MTES: $1 \mathrm{mmol}), \boldsymbol{S} 4$ (TEOS: 19 mmol, PTES: $1 \mathrm{mmol}$ ), $\mathbf{S 5}$ (TEOS: $19 \mathrm{mmol}$, VTES: $1 \mathrm{mmol}$ ).

\subsection{Characterization}

Powder X-ray diffraction (XRD) patterns were recorded using a Seifert RTG DRON-3 diffractometer ( $\mathrm{CuK} \alpha$ radiation) with $0.02^{\circ}$ step size and $10 \mathrm{~s}$ step time over a range of $0.5^{\circ}<2 \theta<5.0^{\circ}$ at room temperature.

Nitrogen adsorption isotherms were measured at $-196^{\circ} \mathrm{C}$ by using an ASAP $2405 \mathrm{~N}$ adsorption analyzer (Micromeritics). Prior to adsorption measurements each sample was degassed (at $110^{\circ} \mathrm{C}$ ).

The content of nitrogen in the obtained samples was determined quantitatively by elemental analysis using PerkinElmer CHN 2400 analyzer and the content of sulphur groups by X-ray fluorescence spectroscopy (XRF) using the Canberra Apparatus.

FT-IR/PAS spectra were recorded by means of a BioRad Excalibur 3000MX spectrometer equipped with photoacoustic detector MTEC300 in the helium atmosphere at 
the resolution of $4 \mathrm{~cm}^{-1}$ and maximum source aperture. The spectra were normalized with reference to MTEC carbon black standard. Interferograms of 512 scans were averaged for each spectrum.

\section{Results and discussion}

\subsection{XRD and TEM results}

Mesostructured materials were obtained under all conditions investigated, except the sample $\boldsymbol{S} 2$. Three well-resolved peaks are observed in the range of $2 \theta \approx 0.1-1.8^{\circ}$ for the samples S1, S3, S4, S5. The peaks can be indexed according to hexagonal p6mm symmetry, indicating a well-defined SBA-15 mesostructure: one sharp reflection at $2 \theta \approx 0.8$ indexed as (100) and two minor but distinct reflections at $2 \theta \approx 1.4$ and 1.8 , indexed as (110) and (200), respectively. Figure 2 presents XRD patterns of the samples $\boldsymbol{S} \boldsymbol{4}$ and $\boldsymbol{S} \mathbf{2}$.

TEM pictures complement the results obtained by XRD method. The arrays of ordered mesopores can be easily seen in Fig. 3, where selected TEM images are presented. In the case of the sample $\boldsymbol{S} \boldsymbol{2}$ only a partial ordering is observedthe amorphous phase is formed around ordered array of mesopores. It is believed that a reason for such a behavior is connected with interactions between amine groups and poly(ethylene oxide) blocks. A strong disruptive effect of ATES (due to the lowering of local $\mathrm{pH}$ ) on the formation of an ordered structure was described elsewhere (Chong et al. 2004).

\subsection{Nitrogen sorption measurements}

Nitrogen isotherms of all samples except for sample $\boldsymbol{S} \mathbf{2}$ have a sharp capillary condensation step, reflecting capillary condensation of adsorbate in the uniform mesopores channels, and evaporation step related to the evacuation of adsorbate from the pores. Thus, a framework of these materials has a uniform array of mesopores with the same diameter, consistent with XRD and TEM data. The type of isotherm observed for sample $\boldsymbol{S} \mathbf{2}$ indicates the absence of ordered mesopores; in fact this sample is rather amorphous, which is also confirmed by XRD data.

The properties of the porous structure are summarized in Table 1 . The pure silica sample $\boldsymbol{S} \boldsymbol{1}$ has the highest $S_{\mathrm{BET}}$ value- $952 \mathrm{~m}^{2} / \mathrm{g}$, samples $\boldsymbol{S 2}-\boldsymbol{S 5}$ have lower values of $S_{\mathrm{BET}}$ in the range $806-914 \mathrm{~m}^{2} / \mathrm{g}$. Pore volumes also differ among the samples investigated. Higher pore volume of the sample $\boldsymbol{S} \mathbf{2}$ is a result of the lack of order and presence of textural unordered mesopores. The rest of the samples have pore volumes in the range $1.20-1.43 \mathrm{~cm}^{3} / \mathrm{g}$. More than $80 \%$ of the total pore volume is connected with the presence of mesopores bigger than $5 \mathrm{~nm}$ and less than $20 \%$ is due to the

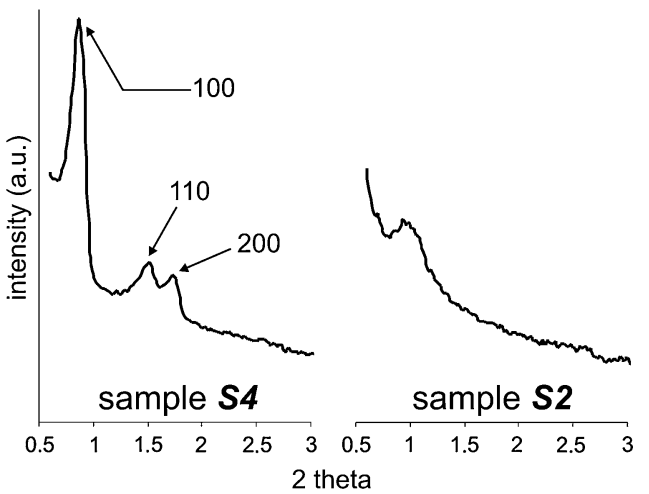

Fig. 2 XRD patterns of the samples $\boldsymbol{S} \mathbf{4}$ and $\boldsymbol{S} \mathbf{2}$

presence of interconnecting pores (micropores and mesopores smaller than $5 \mathrm{~nm}$ ). It should be noted that the sums of the volume of ordered mesopores $\left(V_{2}\right)$ and interconnecting pores $\left(V_{1}\right)$ calculated by KJS method are very close to the values of total single-point pore volumes $\left(V_{\mathrm{p}}\right)$.

Pore sizes of the samples $\boldsymbol{S 1}, \boldsymbol{S 3}-\boldsymbol{S 5}$ were calculated using BJH (Barrett et al. 1951) and KJS (Jaroniec and Solovyov 2006) method ( $d_{\mathrm{BJH}}$ and $d_{\mathrm{KJS}}$, respectively), which are commonly used to calculate pore size distributions of SBA-15 materials. However, the BJH method tends to underestimate the average pore size, so usually the KJS method is recommended for more accurate calculations. Average pore sizes of ordered mesopores of all ordered samples calculated by KJS method are in the range 7.5-9.1 nm. $\mathbf{S 1}$ and $\mathbf{S 5}$ samples have mesopore diameters significantly wider that the samples $\mathbf{S} \mathbf{3}$ and $\boldsymbol{S 4}$. The same tendency is observed in the case of interconnecting pores smaller than $5 \mathrm{~nm}$.

\subsection{Infrared spectroscopy}

FT-IR/PAS spectra of samples $\boldsymbol{S 1 - S 5}$ are shown in Fig. 4. A characteristic property of spectra of all materials is the presence of the most intense and wide absorption band in the region of $1000-1150 \mathrm{~cm}^{-1}$ which has a high-frequency shoulder at $1150-1250 \mathrm{~cm}^{-1}$. The occurrence of this absorption band is definitely attributed to stretching modes of the siloxane framework, $v^{\mathrm{s} \text {,as }}(\equiv \mathrm{Si}-\mathrm{O}-\mathrm{Si} \equiv)$. Bands located at $\sim 450 \mathrm{~cm}^{-1}$ and $\sim 800 \mathrm{~cm}^{-1}$ can be assigned to bending modes of siloxane fragments, $\delta(\equiv \mathrm{Si}-\mathrm{O}-\mathrm{Si} \equiv)$ and outof-plane bending modes of $\mathrm{OH}$ as well as $\mathrm{O}-\mathrm{Si}-\mathrm{OH}$ fragments, respectively (Legrand 1998; Buccuzzi et al. 1978).

The presence of the $-\mathrm{CH}_{2}$ - link in the propyl chain of the co-monomer (ATES, MTES) and in the poly(oxyethylene) and poly(oxypropylene) blocks of the template (Pluronic $\mathrm{P} 123$ ) is confirmed by a group of absorption bands in the region of $2860-3030 \mathrm{~cm}^{-1}$, what can be attributed to stretching modes of $\mathrm{CH}_{2}$ groups, $v^{\mathrm{s} \text {,as }}\left(\mathrm{CH}_{2}\right)$, and possibly $\mathrm{CH}_{3}$ 
Fig. 3 TEM images of the samples $\boldsymbol{S} \boldsymbol{1}$ (top left), $\boldsymbol{S} \boldsymbol{2}$ (top right), $\boldsymbol{S 4}$ (bottom left), $\mathbf{S 5}$ (bottom right)

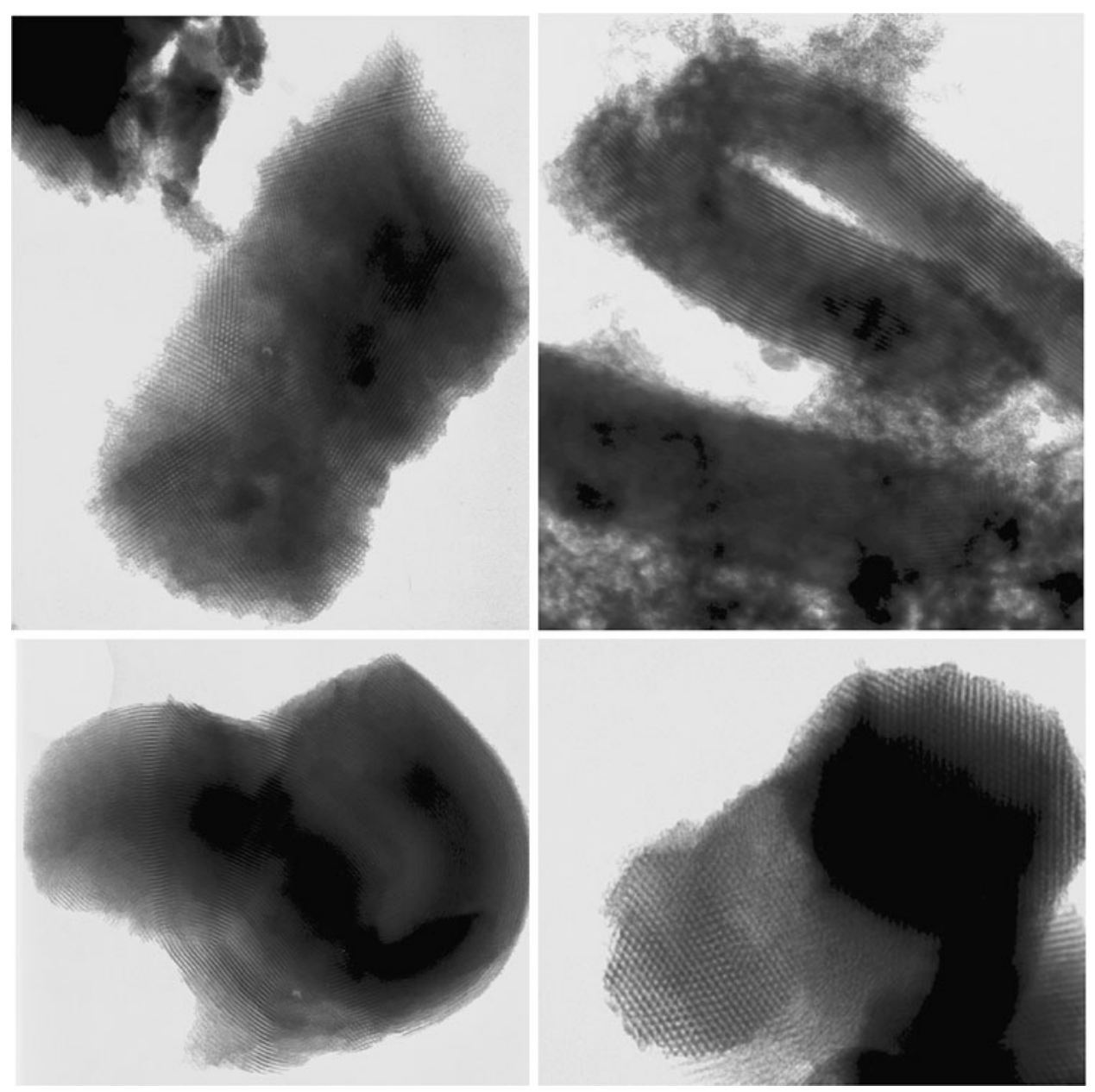

Table 1 Structural and adsorption characteristics of the samples studied

\begin{tabular}{|c|c|c|c|c|c|c|c|c|c|c|}
\hline No. & $\begin{array}{l}\text { Molar ratio } \\
\text { of monomers }\end{array}$ & $S_{\mathrm{BET}^{\mathrm{a}}\left[\mathrm{m}^{2} / \mathrm{g}\right]}$ & $\begin{array}{l}V_{t}^{\mathrm{b}} \\
{\left[\mathrm{cm}^{3} / \mathrm{g}\right]}\end{array}$ & $\begin{array}{l}d^{1} \mathrm{KJS}^{\mathrm{c}} \\
{[\mathrm{nm}]}\end{array}$ & $\begin{array}{l}V_{1}{ }^{\mathrm{d}} \\
{\left[\mathrm{cm}^{3} / \mathrm{g}\right]}\end{array}$ & $\begin{array}{l}d^{2} \mathrm{KJS}^{\mathrm{e}} \\
{[\mathrm{nm}]}\end{array}$ & $\begin{array}{l}V_{2}{ }^{\mathrm{f}} \\
{\left[\mathrm{cm}^{3} / \mathrm{g}\right]}\end{array}$ & $\begin{array}{l}d_{\mathrm{BJH}^{\mathrm{g}}} \\
{[\mathrm{nm}]}\end{array}$ & $\begin{array}{l}a^{\mathrm{h}} \\
{[\mathrm{nm}]}\end{array}$ & $\begin{array}{l}w^{\mathrm{i}} \\
{[\mathrm{nm}]}\end{array}$ \\
\hline$S 1$ & $\begin{array}{l}\text { TEOS } \\
20 \mathrm{mmol}\end{array}$ & 952 & 1.28 & 3.05 & 0.15 & 9.06 & 1.13 & 5.97 & 12.3 & 3.2 \\
\hline$S 2$ & $\begin{array}{l}\text { TEOS:ATES } \\
\text { 19:1 mmol }\end{array}$ & 806 & 2.49 & $-{ }^{*}$ & $-^{*}$ & $-^{*}$ & $-{ }^{*}$ & 11.5 & $-^{*}$ & $-{ }^{*}$ \\
\hline$S 3$ & $\begin{array}{l}\text { TEOS:MTES } \\
\text { 19:1 mmol }\end{array}$ & 885 & 1.20 & 2.49 & 0.27 & 7.66 & 0.98 & 4.58 & 11.8 & 4.1 \\
\hline$S 4$ & $\begin{array}{l}\text { TEOS:PTES } \\
\text { 19:1 mmol }\end{array}$ & 914 & 1.43 & 2.32 & 0.32 & 7.55 & 1.13 & 4.66 & 11.8 & 4.2 \\
\hline$S 5$ & $\begin{array}{l}\text { TEOS:VTES } \\
\text { 19:1 mmol }\end{array}$ & 819 & 1.37 & 3.06 & 0.20 & 9.13 & 1.19 & 5.69 & 11.8 & 2.7 \\
\hline
\end{tabular}

${ }^{a}$ BET specific surface area evaluated in the 0.05-0.25 range of relative pressures (Brunauer et al. 1938), ${ }^{\mathrm{b}}$ Total pore volume calculated by converting the amount adsorbed at a relative pressure about 0.99 to the volume of liquid adsorbate, ${ }^{\mathrm{c}}$ The average size of the pores smaller than $5 \mathrm{~nm}$ by KJS method (Jaroniec and Solovyov 2006), ${ }^{\mathrm{d}}$ The volume of the pores smaller than $5 \mathrm{~nm}$ by KJS method, ${ }^{\mathrm{e}}$ The average size of the pores

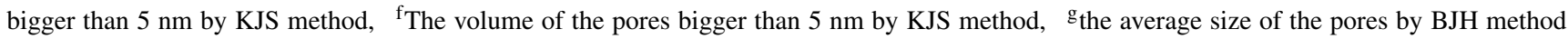
(Barrett et al. 1951), ${ }^{\mathrm{h}}$ unit cell parameter, ${ }^{\mathrm{i}}$ pore wall thickness calculated from: $a-d^{2}{ }_{\mathrm{KJS}}$. ${ }^{*}$ Values not determined 
Fig. 4 FT-IR/PAS spectra of the samples: a) $\boldsymbol{S} \mathbf{1}, b) \boldsymbol{S 2}, c) \boldsymbol{S} \mathbf{3}$, d) $\mathbf{S 4}$, e) $\mathbf{S 5}$
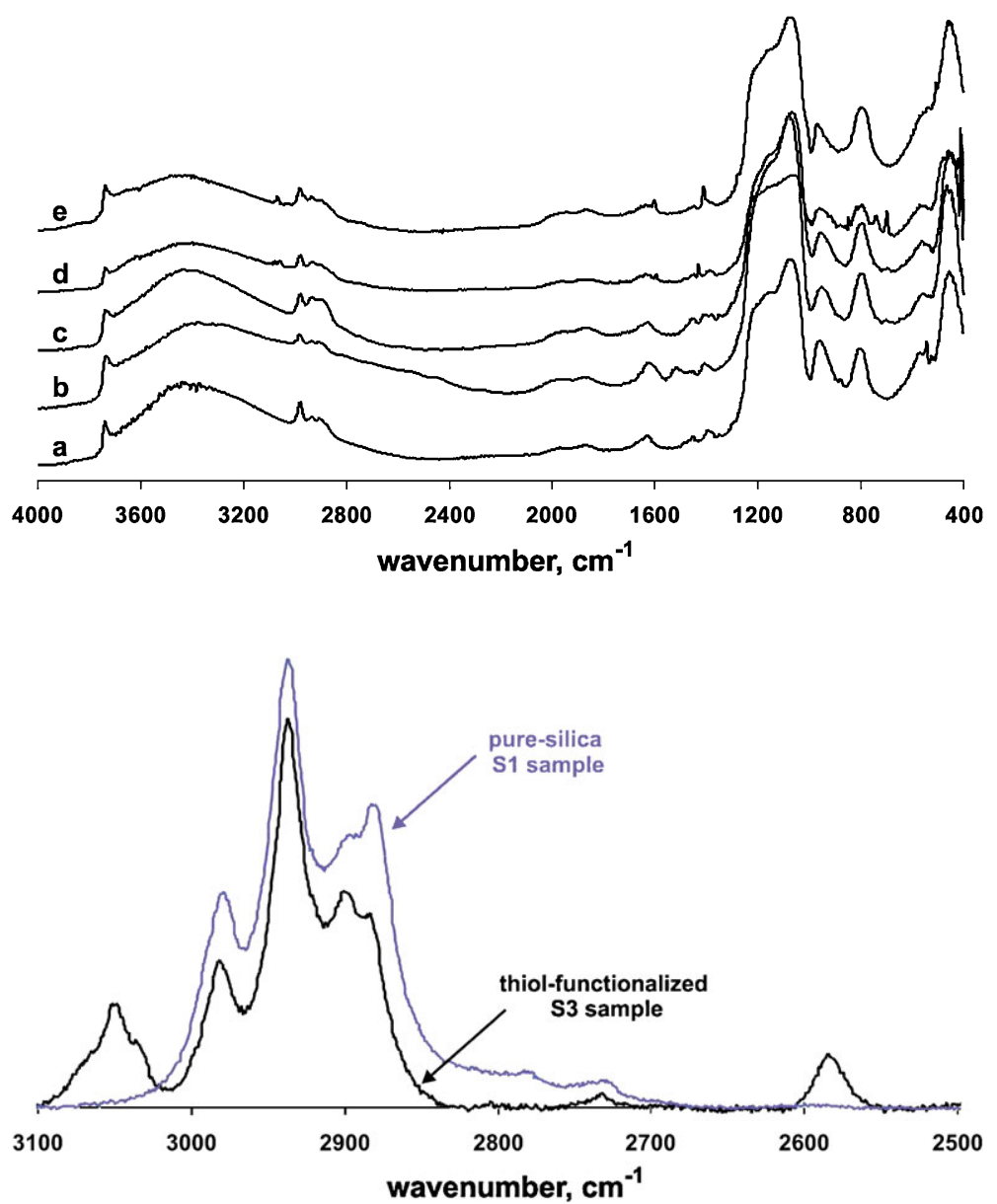

Fig. 5 Fragment of the Raman spectra of the samples $\boldsymbol{S} \mathbf{1}$ and $\boldsymbol{S 3}$ groups, $v^{\mathrm{s}, \mathrm{as}}\left(\mathrm{CH}_{3}\right)$ (fragments of residual ethoxy groups). It is also confirmed by bands in the region of $\sim 1410 \mathrm{~cm}^{-1}$, which can be assigned to bending modes of the $\mathrm{CH}_{2}$ group, $\delta\left(\mathrm{CH}_{2}\right)$.

In the spectra of all samples a sharp, medium intensity band at $3742 \mathrm{~cm}^{-1}$ is assigned to stretching modes of silanol groups, $v(\mathrm{OH})$. On the red wing of this band, down to $3000 \mathrm{~cm}^{-1}$, a wide band is observed with the maximum close to $3450 \mathrm{~cm}^{-1}$. This band arises from the stretching mode, $v(\mathrm{OH})$, of the physically adsorbed water. Lowintensity absorption band at $\sim 1635 \mathrm{~cm}^{-1}$ in the IR spectra of all samples corresponds to bending vibrations of water, $\delta\left(\mathrm{H}_{2} \mathrm{O}\right)$.

The presence of vinyl and phenyl functional groups introduced by co-condensation of TEOS with the proper monomer can be confirmed by careful analysis of IR spectra of samples $\boldsymbol{S 4}$ and $\boldsymbol{S 5}$. In the case of sample $\boldsymbol{S} \boldsymbol{4}$ functionalized by phenyl groups, several bands characteristic for Ar species are observed, confirming the presence of aromatic rings in the structure. Two low intensity bands located at $\sim 3085 \mathrm{~cm}^{-1}$ and $\sim 3065 \mathrm{~cm}^{-1}$ are attributed to Ar-H stretching modes, $v(\mathrm{Ar}-\mathrm{H})$, while these at $1600 \mathrm{~cm}^{-1}$ and $1430 \mathrm{~cm}^{-1}$ — to Ar stretching modes of benzene rings frequently coupled to $\mathrm{Ar}-\mathrm{H}$ rocking vibration, $v^{\mathrm{s}}(\mathrm{Ar})$ and $v^{\text {as }}(\mathrm{Ar})$, respectively. Moreover, in the fingerprint region at $745 \mathrm{~cm}^{-1}$ and $700 \mathrm{~cm}^{-1}$ there are two absorption bands characteristic for mono-substituted benzene rings. The former is due to Ar-H out-of-plane bending, $\gamma(\mathrm{Ar}-\mathrm{H})$, and the latter-to the ring torsion $\gamma(\mathrm{Ar})$.

In the spectrum of sample $\mathbf{S} \boldsymbol{5}$ functionalized by vinyl groups a low intensity absorption band at $3075 \mathrm{~cm}^{-1}$, corresponding to stretching mode of methylidene fragments, $v^{\text {as }}\left(=\mathrm{CH}_{2}\right)$, is observed. In addition, a band at $1606 \mathrm{~cm}^{-1}$ corresponds to stretching mode of $\mathrm{C}=\mathrm{C}$ fragment, $v(\mathrm{C}=\mathrm{C})$.

In the case of the sample $\boldsymbol{S} \boldsymbol{2}$ which contains amino groups, it is impossible to find characteristic signals of amino groups due to the low concentration of APES. In particular, two absorption bands corresponding to the stretching $\mathrm{NH}$ modes, $v^{\mathrm{s} \text {,as }}(\mathrm{NH})$, normally located in the region of 3300-3500 $\mathrm{cm}^{-1}$, cannot be observed due to the presence of a wide band of the physically adsorbed water. However, an increase in the intensity of the absorption band at $\sim 1635 \mathrm{~cm}^{-1}$, corresponding only to $\delta\left(\mathrm{H}_{2} \mathrm{O}\right)$ but also to $\delta\left(\mathrm{NH}_{2}\right)$, seems to be some indication of the presence of the amino groups. 
Fig. 6 FT-IR/PAS spectra of pure-silica $\boldsymbol{S} \boldsymbol{1}$ sample: (a) as synthesized, (b) after $2^{\text {nd }}$ extraction, (c) after $4^{\text {th }}$ extraction

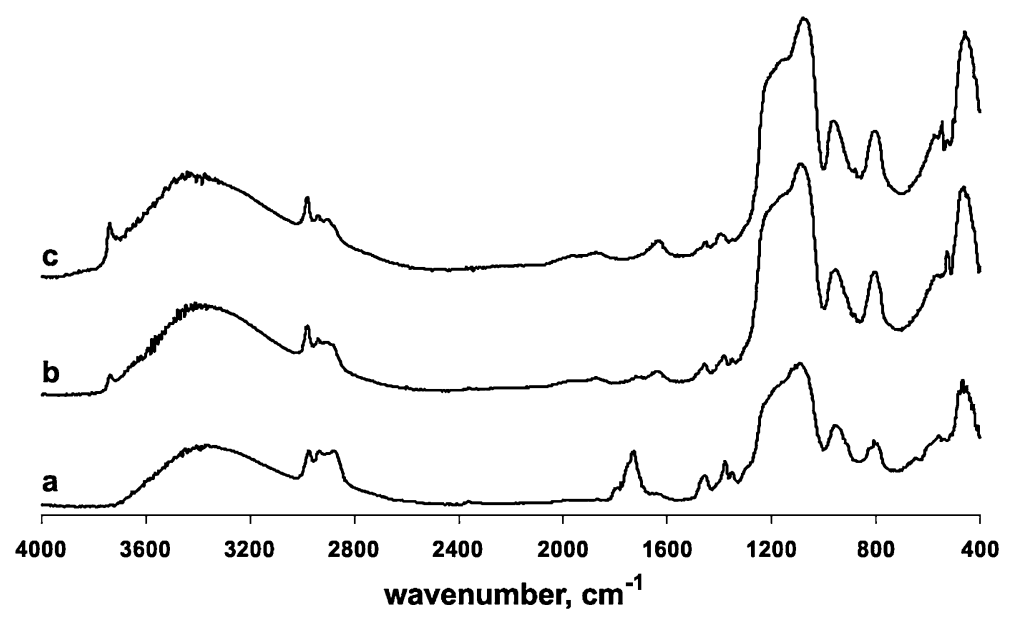

The presence of thiol groups in the sample $\boldsymbol{S} 3$ could not be detected by means of FT-IR/PAS spectroscopy due to low concentration of MTES used in the synthesis. However, we were able to detect qualitatively the thiol groups by means of Raman spectroscopy. A part of the Raman spectrum for the samples $\boldsymbol{S 1}$ and $\boldsymbol{S 3}$ are presented in Fig. 5. The presence of the band at $2580 \mathrm{~cm}^{-1}$, attributed to SH stretching mode, $v(\mathrm{SH})$, is a clear evidence of the successful co-condensation between TEOS and MTES.

FT-IR/PAS spectroscopy was also used to study the removal of template from the samples. Figure 6 presents spectra of the pure-silica $\boldsymbol{S} \boldsymbol{1}$ sample at different stages of extraction. The intensity of the signals in the region of 2860 $3030 \mathrm{~cm}^{-1}$ is decreasing after each extraction step. However, the signals do not disappear even after four extraction processes what indicates that trace amounts of the template are still present in the final sample.

Interesting conclusion can be drawn from the intensity of the signal at $3742 \mathrm{~cm}^{-1}$ corresponding to valence modes of silanols. This signal is not observed in the case of as-synthesized sample and is gradually increasing after each extraction step. This means that the main part of silanol groups present in the final materials do not come from uncompleted condensation during the synthesis, but is rather formed in the course of the extraction process.

The nitrogen and sulfur contents for samples $\boldsymbol{S} 2$ and $\boldsymbol{S 3}$ obtained by elemental analysis represent around 55\% and $75 \%$, respectively, of the values estimated on the basis of the initial molar composition of the synthesis mixture. For this type of preparation these values represent quite good efficiency of incorporation of the above-mentioned functionalities. Apparently, significant part of the amine groups is lost during the extraction process. The content of phenyl and vinyl functionalities in the samples $\boldsymbol{S} \boldsymbol{4}$ and $S 5$ was difficult to estimate due to the presence of some small amount of unextracted template in the final samples.

\section{Conclusions}

Highly ordered SBA-15 organosilicas functionalized with thiol, vinyl and phenyl groups have been obtained by cocondensation of TEOS and proper monomers. These functionalities may be used for further chemical reactions or adsorption of appropriate sorbates. XRD, TEM and nitrogen adsorption/desorption data confirm high degree of ordering. The elemental analysis and FT-IR/PAS data shows that co-condensation between TEOS and alkoxysilanes was successful and the final samples contain introduced functional groups. The FT-IR/PAS testify to the presence in the SBA15 samples uncondensed silanol groups. Interestingly, these groups are not present in as-synthesized samples but appear during extraction process. It is also deduced that traces of the Pluronic are present in the final samples after extraction process.

Acknowledgements The research leading to these results has received funding from the European Community's Seventh Framework Programme (FP7/2007-2013) under a Marie Curie International Research Staff Exchange Scheme, Grant Agreement No PIRSES-GA2008-230790.

M.B. and A.D. acknowledge the Polish Ministry of Science and Higher Education for supporting the research under Grant No. N N204 111135.

Authors also thank to prof. Mietek Jaroniec for his help with analyzing nitrogen adsorption/desorption data using KJS method.

Open Access This article is distributed under the terms of the Creative Commons Attribution Noncommercial License which permits any noncommercial use, distribution, and reproduction in any medium, provided the original author(s) and source are credited.

\section{References}

Andersson, J., Rosenholm, J., Areva, S., Linden, M.: Chem. Mater. 16, 4160 (2004)

Barrett, E.P., Joyner, L.G., Halenda, P.: J. Am. Chem. Soc. 73, 373 (1951) 
Beck, S., et al.: J. Am. Chem. Soc. 114, 10834 (1992)

Brunauer, J.S., Emmet, P.H., Teller, E.: J. Am. Chem. Soc. 60, 309 (1938)

Buccuzzi, F., Coluccia, S., Ghiotti, G., Morterra, C., Zecchina, A.: J. Phys. Chem. 82, 1298 (1978)

Chong, A.S., Zhao, X.S., Kustedjo, A.T., Qiao, S.Z.: Microporous Mesoporous Mater. 72, 33 (2004)

Gierszal, K.P., Kim, T.-W., Ryoo, R., Jaroniec, M.: J. Phys. Chem. B 109, 23263 (2005)

Goltner, C.G., Henke, S., Weissenberger, M.C., Antonietti, M.: Angew. Chem. Int. Ed. 37, 613 (1998)

Grudzien, R.M., Grabicka, B.E., Knobloch, D.J., Jaroniec, M.: Colloids Surf. A, Physicochem. Eng. Asp. 291, 139 (2006)

Jaroniec, M., Solovyov, L.A.: Langmuir 22, 6757 (2006)
Kresge, C.T., Leonowicz, M.E., Roth, W.J., Vartuli, J.C., Beck, J.S.: Nature 359, 710 (1992)

Legrand, A.P. (ed.): The Surface Properties of Silicas. Wiley, New York (1998)

Olkhovyk, O., Jaroniec, M.: Adsorption 11, 205 (2005)

Olkhovyk, O., Antochshuk, V., Jaroniec, M.: Colloids Surf. A 236, 69 (2004)

Rosenholm, J.B., Rahiala, H., Puputti, J., Stathopolous, V., Pomonis, P., Beurroies, I., Backfolk, K.: Colloids Surf. A 250, 289 (2004)

Zhao, D.Y., et al.: Science 279, 548 (1998a)

Zhao, D.Y., et al.: J. Am. Chem. Soc. 120, 6024 (1998b) 